\title{
Investigation and treatment of facial paralysis
}

Acute lower motor neurone facial paralysis is a common presentation in childhood. In most cases, an aetiological agent is not identified and the condition resolves spontaneously. A small number of cases are caused by a variety of underlying pathologies - some of which may have significant morbidity and mortality associated with them.

The facial nerve (VII) leaves the pons at the pontomedullary junction, enters the skull via the internal auditory meatus, and passes along the facial canal. The nerve passes in close proximity to the medial wall of the inner ear and the mastoid cavity. During its course through the petrous temporal bone, branches leave to supply the lacrimal glands, the stapedius muscle in the inner ear, sensation for auricular skin, the sublingual and submandibular salivary glands, and taste fibres to the anterior two thirds of the tongue. The facial nerve exits the skull via the stylomastoid foramen and terminal branches supply the muscles of facial expression.

Bilateral cortical innervation of the muscles of the upper face (orbicularis oculi and frontalis) means that complete facial paralysis is only seen with lower motor neurone lesions. The extent of additional impairment depends on the site of injury. Proximal lesions are associated with impaired lacrimation, hyperacusis, and loss of taste on the anterior two thirds of the tongue.

The pathophysiology of idiopathic facial nerve palsy is uncertain. The condition often occurs two to three weeks following a viral illness. Active viral invasion of the nerve or immune demyelination may be responsible for the underlying neuropathy. It is unclear as to whether physical swelling of the nerve plays a significant pathological role. A variety of specific pathologies can also produce an acute lower motor neurone facial paralysis. Table 1 lists some important examples. Acute facial paralysis may manifest itself as a presenting symptom of one such specific disease, or, as is more common, occur as a complication during the course of a recognised illness.

Table 1 Diverse aetiologies of acquired facial nerve paralysis

Infective or inflammatory

Otitis media

Mastoiditis

Herpes zoster (Ramsay Hunt syndrome ${ }^{19}$ )

Temporal lobe abscess

Varicella

Mumps

Meningitis

Encephalitis

Mycoplasma $^{16}$

Cat scratch disease ${ }^{26}$

Kawasaki disease

Guillain-Barre syndrome

$\mathrm{HIV}^{27}$

Lyme disease

Trauma

Facial burn ${ }^{28}$

Basal skull fracture

Blunt and penetrating trauma

Facial surgery

Neoplastic

Leukaemia

Cerebellar astrocytoma

Rhabdomyosarcoma

Haematological

Haemophilia $^{29}$

Histiocytosis

Congenital

Melkersson-Rosenthal syndrome

Osteopetrosis ${ }^{28}$

Intracerebral arteriovenous malformation ${ }^{28}$

Other

Hypertension
The term "Bell's palsy" refers to a facial palsy of rapid onset related to a lesion of the nerve within the facial canal. ${ }^{1}$ While the majority of authors use the eponym to describe idiopathic facial palsy alone, this is not universal. Descriptive terms are less open to confusion and tend to focus the mind on potential differential diagnoses.

Controversy exists as to the appropriate investigation of children presenting with acute facial paralysis. A full clinical history should be taken, and a detailed physical examination performed. Children with atypical signs or symptoms require urgent specialist referral (see table 2). Otoscopy is mandatory in all patients presenting with facial paralysis. Where adequate auditory acuity cannot be confirmed an audiogram should be arranged. Hypertension is a rare but well recognised cause of facial paralysis ${ }^{2}$; all children must have their blood pressure checked.

The utility of further investigation, in the absence of additional symptoms or specific findings on physical examination, is debatable.

Radiological imaging is essential if additional neurological abnormalities are identified or if malignancy is suspected. Magnetic resonance imaging is especially helpful in identifying brainstem pathology. High resolution computed tomography scanning is better in the evaluation of the intratemporal portion of the nerve. ${ }^{3}$ Contrast enhanced magnetic resonance imaging can identify sections of affected nerve in idiopathic facial palsy. ${ }^{4}$ This expensive and invasive test is not indicated in the majority of children.

Facial paralysis is a recognised feature of leukaemic recurrence in both adults and children. A small number of cases of facial paralysis in children, occurring as a presenting feature of leukaemia, have also been described. As a result, some authorities have recommended the routine performance of a full blood count for all children presenting with acute lower motor neurone facial paralysis. ${ }^{5}$ We have identified six reported cases of leukaemia presenting with facial paralysis in children. ${ }^{6-11}$ In all but one case, ${ }^{7}$ additional symptoms, documented at presentation, would prompt further investigation. Haematological findings are documented in four of the reports. ${ }^{8-11}$ Although abnormalities of the blood count were present in each case, changes can be subtle and initial haematological findings were discounted or overlooked in three of the four cases.

Neurophysiological studies can help to provide prognostic information and are useful in evaluating lesions that have not resolved at one month. While several tests exist, many require significant cooperation on behalf of the subject. Two of the simpler tests are the measurement of fibrillation potentials (as part of electromyography) and recording of the blink reflex. Fibrillation potentials are detectable in muscles, which have lost their innervation, after approximately three weeks. Their presence implies significant axonal degeneration. Blink reflex tests utilise

Table 2 Symptoms and signs indicative of possible additional pathology, urgent specialist referral required

Ear ache

Hearing loss

Pain or paraesthesia

Any abnormality on otoscopy - including otitis media

Associated cranial neuropathies or other neurological signs

Hypertension

Lymphadenopathy, pallor or bruising

Vesicles in external meatus or on soft palate

Single branch involvement

Gradual progression of paralysis beyond 3 weeks

Recurrence

Mastoid swelling 
the polysynaptic nature of this reflex. Unilateral stimuli, transmitted via the trigeminal nerve $(\mathrm{V})$, produce an early ipsilateral facial (VII) motor response, followed by a bilateral late response. A variety of stimuli can be used to elicit the reflex, for example, electrical stimulation of the supraorbital nerve or a puff of air directed onto the cornea. Recordings are made from electrodes placed over both infraorbital ridges. Absence or delay in the late response can be used to assess facial innervation. Neither test can provide useful information in the acute setting, nor can they differentiate the pathological processes responsible. None the less, such tests can provide objective assessment of facial nerve function and reassure parents and children.

The treatment of idiopathic facial palsy is also controversial. The use of steroids early in the course of the disease has been suggested as a way of reducing the duration of paralysis and the risk of long term impairment. A meta-analysis of randomised control trials, performed in adults, seems to support this view. ${ }^{12}$ A larger portion of patients treated with steroids recovered completely and mean time to recovery was shorter. Treatment appears to be more effective when started within 24 hours of onset. ${ }^{13}$ The benefits of steroid treatment have yet to be proven in children. ${ }^{14}$ As the vast majority of children will recover completely, with or without treatment, a very large intervention study would be required to show any significant effect.

Herpes simplex and varicella zoster viruses have been implicated in the pathogenesis of idiopathic facial palsy, ${ }^{15} 16$ and the routine use of antiviral agents has been suggested. A study of adult patients suggests that acyclovir alone is less efficacious than steroid treatment. ${ }^{17}$ The use of acyclovir in combination with steroids does not improve the outcome of idiopathic facial palsy. ${ }^{18}$

Ramsay Hunt syndrome (or herpes zoster oticus) is caused by varicella zoster virus reactivation in the geniculate ganglion. Unilateral facial paralysis is accompanied by herpetic vesicles in the external auditory canal or on the soft palate. The prognosis for this condition is not as good as that of idiopathic facial palsy. ${ }^{19}$ Aggressive treatment with intravenous acyclovir, possibly in combination with steroids, is recommended.

A number of other treatments, aimed at improving outcome in idiopathic facial palsy, have been reported in adults. In an open, randomised trial, patients treated with vitamin $B_{12}$, alone or in combination with steroids, recovered faster than those treated with steroids alone.$^{20}$ In a randomised, blind study, patients treated with $100 \%$ hyperbaric oxygen recovered faster than those treated with steroids and $7 \%$ oxygen at the same pressure. Outcome was also improved in the group receiving the higher oxygen concentration. $^{21}$

Surgical decompression of the facial nerve canal is no longer considered an effective, or appropriate, treatment for patients with idiopathic facial palsy.

Persistent facial weakness has considerable functional and cosmetic implications. Disfigurement can lead to significant psychosocial morbidity. The small numbers of children falling into this group require expert assessment. Feedback training and exercise programmes have been shown to provide some benefit in adult patients with long standing facial nerve paralysis. ${ }^{22}$ Surgical techniques, aimed at improving function and cosmesis, include nerve repair, graft, or transposition. Nerve transposition involves attaching the distal end of the affected facial nerve to another afferent cranial nerve trunk, for example, the contralateral facial nerve, or a hypoglossal "jump graft". This technique must be undertaken within two years of paraly- sis. ${ }^{23}$ Muscle transposition, or microneurovascular free muscle transfer, can also be considered.

In summary, patients presenting with acute lower motor neurone facial paralysis require a thorough physical examination. Full neurological examination, otoscopy, and blood pressure measurement are mandatory. In the absence of any abnormal symptoms or signs, further investigation is unnecessary. To date there is no clear evidence that any form of treatment improves outcome of idiopathic facial palsy in children. Ninety five per cent of children will recover full function, ${ }^{24}{ }^{25}$ most within the first three weeks of the illness. Protection of the cornea, with artificial tears and overnight patching, is normally all that is required. Follow up is advisable. Neurophysiological assessment is helpful in patients with weakness persisting beyond three weeks.

M RIORDAN

Accident and Emergency Department, Birmingham Children's Hospital, Steelhouse Lane, Birmingham $\mathrm{B} 4$ 6NH, UK

Correspondence to: Dr Riordan mriordan@doctors.org.uk

1 Weatherall DJ. Oxford textbook of medicine, 3rd ed. Oxford: Oxford University Press, 1996.

2 Lloyd AV, Jewitt DE, Still JD. Facial paralysis in children with hypertension. Arch Dis Child 1966;41:292-4.

3 Schwaber MK, Zealear D, Netterville JL, et al. The use of magnetic resonance imaging with high-resolution CT in the evaluation of facial resonance imaging with high-resolution CT in the e

4 Tien R, Dillon WP, Jackler RK. Contrast-enhanced MR imaging of the facial nerve in 11 patients with Bell's palsy. AfNR Am F Neuroradiol 1990; 11:735-41

5 Brown JK. Diseases of the peripheral nervous system. In: Campbell AGM, McIntosh N, eds. Forfar and Arneil's textbook of paediatrics. Edinburgh: Churchill Livingstone, 1998:725.

6 Grundfast KM, Guarisco JL, Thomsen JR, Koch B. Diverse etiologies of facial paralysis in children. Int f Pediatr Otorhinolaryngol 1990;19:223-39. 7 Manning JJ, Adour KK. Facial paralysis in children. Pediatrics 1972;49:102-

8 Zappia JJ, Bunge FA, Koopmann CF Jr, McClatchey KD. Facial nerve paresis as the presenting symptom of leukemia. Int $\mathcal{F}$ Pediatr Otorhinolaryngol 1990;19:259-64.

9 Levy R, Har-El G, Segal K, Sidi J. Acute myelogenous leukemia presenting as facial nerve palsy. A case report. Int $\mathcal{F}$ Pediatr Otorhinolaryngol 2:49-53.

10 Todd NW Jr, Bowman CA. Acute myelogenous leukemia presenting as atypical mastoiditis with facial paralysis. Int $\mathcal{f}$ Pediatr Otorhinolaryngol $1984 ; 7: 173-7$

11 Wright JLW. Acute leukaemia presenting as acute mastoiditis. $\mathcal{F}$ Laryngol Otol 1971;85:1087-91

12 Williamson IG, Whelan TR. The clinical problem of Bell's palsy: is treatment with steroids effective? Br f Gen Pract 1996;46:743-7.

13 Shafshak TS, Essa AY, Bakey FA. The possible contributing factors for the success of steroid therapy in Bell's palsy: a clinical and electrophysiological study. F Laryngol Otol 1994;108:940-3.

14 Unuvar E, Oguz F, Sidal M, Kilic A. Corticosteroid treatment of childhood Bell's palsy. Pediatr Neurol 1999;21:814-16.

15 Murakami S, Mizobuchi M, Nakashiro Y, et al. Bell palsy and herpes simplex virus: identification of viral DNA in endoneurial fluid and muscle. Ann Intern Med 1996;124:27-30.

16 Morgan M, Moffat M, Ritchie L, et al. Is Bell's palsy a reactivation of varicella zoster virus? F Infect 1995;30:29-36.

17 De Diego JI, Prim MP, De Sarria MJ, et al. Idiopathic facial paralysis: a randomized, prospective, and controlled study using single-dose prednisone versus acyclovir three times daily. Laryngoscope 1998;108:573-5.

18 Ramos MA, De Miguel Martinez I, Martin Sanchez AM, et al. The incorporation of acyclovir into the treatment of peripheral paralysis. A study of 45 cases [in Spanish]. Acta Otorrinolaringol Esp 1992;43:117-20.

19 Bjerkhoel A, Hyden D. Ramsay-Hunt syndrome in a preschool infant. ORL f Otorhinolaryngol Relat Spec 1989;51:251-4.

20 Jalaludin MA. Methylcobalamin treatment of Bell's palsy. Methods Find Exp Clin Pharmacol 1995;17:539-44.

21 Racic G, Denoble PJ, Sprem N, et al. Hyperbaric oxygen as a therapy of Bell's palsy. Undersea Hyperb Med 1997;24:35-8.

22 Ross B, Nedzelski JM, McLean JA. Efficacy of feedback training in long-standing nerve paresis. Laryngoscope 1991;101:744-50.

23 Shapiro AM, Schaitkin BM, May M. Facial paralysis in children. In: Paediatric otolaryngology. Philadelphia: WB Saunders Co., 1996.

24 Inamura $H$, Aoyagi $M$, Tojima $H$, et al. Facial nerve palsy in children: clinical aspects of diagnosis and treatment. Acta Otolaryngol Suppl 1994;511:150-2.

25 Prescott CA. Idiopathic facial nerve palsy in children and the effect of treatment with steroids. Int $\mathcal{F}$ Pediatr Otorhinolaryngol 1987;13:257-64.

26 Walter RS, Eppes SC. Cat scratch disease presenting with peripheral facial nerve paralysis. Pediatrics 1998;101:E13.

27 Amayo EO, Kwasa TO. HIV and acute peripheral facial nerve palsy. East Afr Med f 1991;68:948-51.

28 Grundfast KM, Guarisco JL, Thomsen JR, Koch B. Diverse etiologies of facial paralysis in children. Int $\mathcal{F}$ Pediatr Otorhinolaryngol 1990;19:223-39.

29 Ray M, Ezhilarasan R, Marwaha RK, et al. Facial nerve palsy in an infant with hemophilia A. Pediatr Hematol Oncol 1999;16:71-4. 


\section{The "How!" sign — a central palmar blister induced by overplaying on a Nintendo console}

How did this right handed 8 year old in figure 1 contract the central palmar blister? The complete story is seen in figure 2 . Running on the screen in the background is the Nintendo game, Mario Party, which he and two friends had hired from the local video shop for the afternoon. In his left hand is the Nintendo control console with its central joystick. After the main game, the manufacturers have added a series of four "minigames". In two of these minigames, Tug of War and Pedal Power, the player has to rotate the central joystick with the palm of his hand for as long and as fast as possible to be victorious. All three children developed the "How!" sign within half an hour.

Treatment was administered in the form of Mickey Mouse plasters to all three palms and

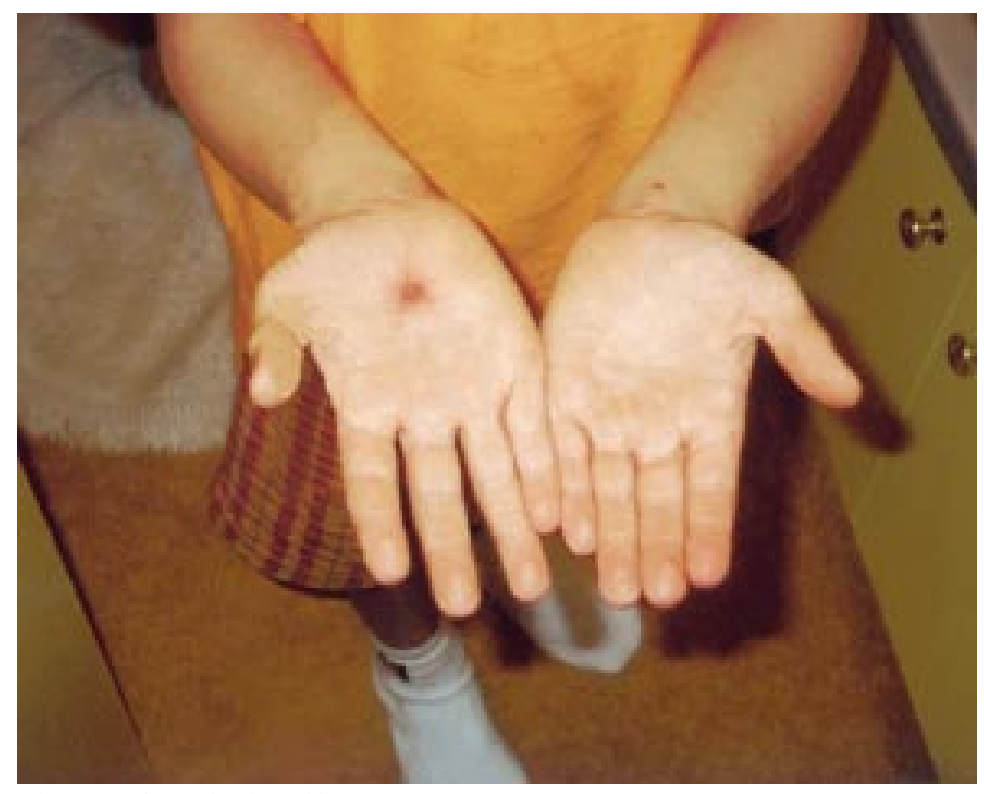

Figure 1 Central palmar blister the boys immediately continued the game and rubbed off their plasters. Their raw blisters then effectively put a stop to their collective madness.

DR JOHANNA WOOD 10 The Woodlands, Chelsfield Park, Orpington, Kent BR6 6HL, UK woodies100@hotmail.com

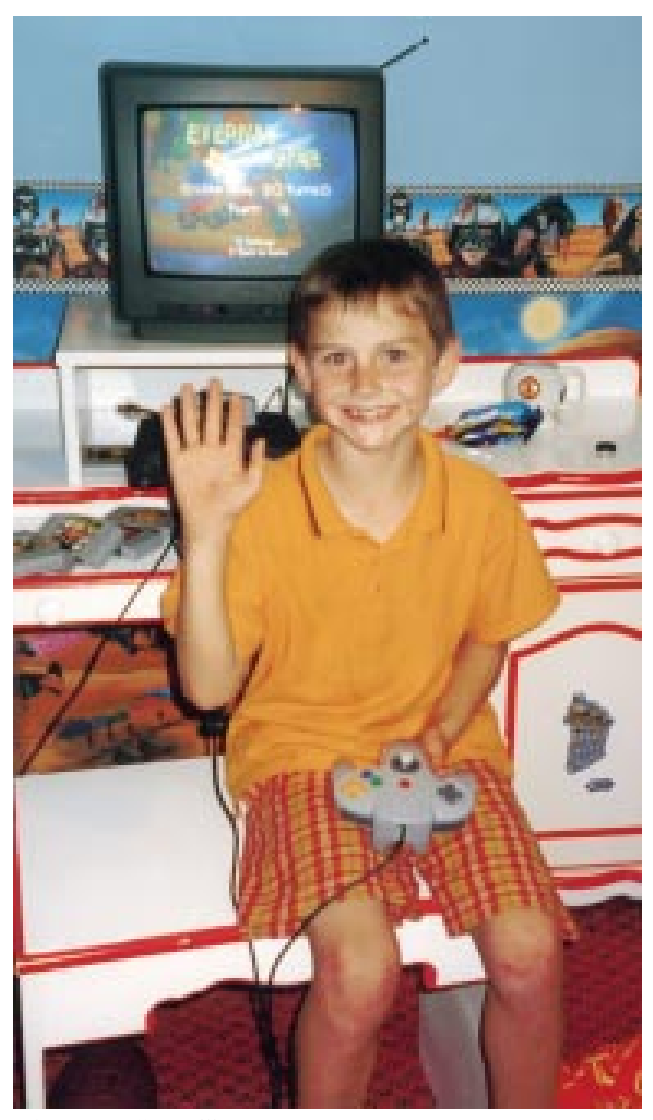

Figure 2 "How!" 